\title{
Evaluation of industrial engineering students' competencies for process improvement in hospitals
}

\author{
Lukasz M. Mazur ${ }^{1}$, Shi-Jie (Gary) Chen $^{2}$ \\ ${ }^{1}$ North Carolina State University (UNITED STATES); ${ }^{2}$ Northern Illinois University (UNITED \\ STATES) \\ lukaszmazun@,ncsu.edu; garychen@,niu.edu
}

Received September 2010

Accepted December 2010

\begin{abstract}
The failures to properly educate students about process improvement can be seen as major factor leading to increased risks of patient safety and increased wastes in hospital settings. The purpose of this research was two-fold: 1) to identify characteristics that explain the efficacy of Plan-Do-Study-Act (PDSA) based-tools while used by Industrial Engineering (IE) students on multidisciplinary teams in hospital; 2) to identify competencies needed by IEs for effective process improvement in hospital using PDSA based-tools. Exploratory mixed method design approach with survey study, unstructured interviews, and focus group discussions was used to collect the data. A regression analysis was used to identify PDSA based-tool characteristics perceived by IE students as instrumental for process improvement. Next, the abductive inference was applied to analyze qualitative data in order to investigate competencies needed for effective process improvement using PDSA based-tools. Using regression analysis, we found the brainstorming via visualization, recognizing root-cause(s) of the problem and selecting improvement measures via linking the process flow with task(s) characteristics to be the significant characteristics. From qualitative data analysis, we learned that IE students strived in technical analysis but lacked competencies in analyzing qualitative data needed for change implementation efforts. There is increasing evidence that success in achieving process improvement goals is at least partially attributable to implementation processes and contexts and not just to the nature of the technical solution. Therefore, IE students interested in working in hospitals must develop new competencies related to qualitative data analysis to manage change initiatives.
\end{abstract}


Keywords: process improvement, quality improvement, healthcare education

\section{Introduction}

Over the decade, increasing focus on the need to better prepare hospital workforce for quality and cost improvements has centered on continuous improvement methodologies (IOM, 2005), as virtually any improvement activity requires some degree of experimentation and participation of members from diverse functional departments (Deming, 1986). Experts speculate that long-term organizational effectiveness depends on improvement strategies that require close interrelationships among key personnel in various functions (Lei et al, 1996; Brown and Duguis, 1998; Soo, et al., 2002; Dutton, 1993; Anderson et al., 2006). Furthermore, because process improvement leads to formation of new behavior, which supports acquisition of new knowledge and skills by employees, we believe that Plan-Do-Study-Act (PDSA) cycle is in fact a critical element for effective continuous improvement in hospitals. Scholars and leading healthcare improvement organizations have been promoting PDSA based-tools for process improvement to hospitals as one of the primary ways to enhance multidisciplinary efforts to increase quality and patient safety (IOM, 2005; Jimmerson et al., 2005; Mazur and Chen, 2008b). However, the literature shows that spearheading improvements is challenging and difficult, no matter which method or tool is used, because it requires coordination and agreement among many stakeholders, each holding a set of critical information needed for effective problem resolution (Hackman and Wageman, 1995; MacDuffie, 1997; Pelled et al., 1999; Hug and Martin, 2000). Therefore, despite the enormous potential of PDSA cycle for process improvement, little is known about characteristics of PDSA based-tools that make them effective while used on multidisciplinary teams in hospitals. Such deficits in knowledge can lead into improper use of such tools in the hospital environment and poor educational training of process improvement to students.

In this study, using a survey, unstructured interviews and focus group meetings we worked with fifteen senior-level Industrial Engineering (IE) students assigned to solve operational problems using PDSA based-tools at two hospitals. The objective of this research was two-fold: 1 ) to identify characteristics that explain the efficacy of PDSA based-tools while used by IEs on multidisciplinary hospital teams; 2) to 
identify competencies needed by IEs for effective process improvement in hospital using PDSA based-tools.

\section{Background information}

The concept of the PDSA cycle was originally developed by Walter Shewhart, the revolutionary statistician who developed statistical process control in the Bell Laboratories in the U.S. during 1930s. It is often referred to as the Shewhart Cycle. It was taken up and promoted very effectively from 1950s by the famous Quality Management authority, W. Edwards Deming, and is consequently known by many as the Deming Wheel. The PDSA cycle consists of four stages that the investigator must go through to get from 'problem faced' to 'problem solved'. In summary, at each stage the investigator performs the following activities:

I. Stage 1: Plan to improve your operations by identifying the problems and come up with ideas for solving these problems.

II. Stage 2: Do changes that are designed to solve the problems on a small or experimental scale.

III.Stage 3: Study whether the experimental changes are achieving the desired result or not.

IV. Stage 4: Act to implement changes on a larger scale if the experiment is successful.

If the experiment was not successful, skip the Act $(A)$ stage and go back to the Plan (P) stage to come up with some new ideas for solving the problem and go through the cycle again. PDSA describes the overall stages of improvement activities, but how is each stage carried out? According to Deming, PDSA should be repeatedly implemented to increase knowledge of the undertaken with each cycle bringing the investigator closer to the ultimate goal (Deming, 1986). Such approach is based on the belief that the investigator's knowledge and skills are limited, but improved with each iteration. With the improved knowledge at each iteration, the investigator may choose to refine or alter the ultimate goal. However, what are the instrumental characteristics of the PDSA based-tools while used on multidisciplinary teams in hospital? To answer this question, in Section A, we review a body of knowledge dedicated to boundary objects (BOs). Section B presents the "Map-to-Improve" tool used as a BO in our research with IE students. 


\subsection{Boundary Objects (BOs)}

BOs are physical objects that serve as an interface between different communities (Star and Griesemer, 1989). They do not necessarily contain sufficient details to be understandable by all communities, however, neither party is required to understand the full context of use by the other - BOs serve as point of mediation and negotiation around intent (Star and Griesemer, 1989). This is possible because BOs are flexible in group use and more focused while used by individual in isolation (Carlilie, 2004). Very often BOs depend on cognitive information processing of individuals looking at various forms of nonverbal knowledge captured to some degree through interaction with sketches, drawings and/or numbers (Henderson, 1995, 1998). As such, the capacity of PDSA based-tools to be flexible for various uses and users and thus to facilitate differential readings qualifies them as BO.

Researchers found that BOs must possess certain key characteristics to be considered effective for use on multidisciplinary teams. For example, Berg and Bowker (1997) found that a patient's medical record serving as a construction of the patient and the constitution of the hospital staff becomes highly relevant BO between physicians because of its abilities to combine/arrange different pieces of information about the patient without the need for memorization. Yakura (2002) investigated the role of visual artifacts as BOs during project management activities and found them effective because of its abilities to facilitate communication with others via visual representation. Henderson (1991) found that hand sketches facilitated knowledge integration between designers and production personnel in designing a new turbine engine package. She further discovered that designers sought input from the production personnel by generating creative improvement ideas via drawing and re-drawing sketches, which resulted in brainstorming and eventually development of collective new knowledge. Carlile (2002) investigated the role of BOs in the development of new safety valves for a manufacturing firm. In particular, he identified three characteristics of effective BO: 1) must establish a common language and meaningful indicators to measure progress; 2) must provide mechanisms for linking design characteristic with work context and the associated concerns; 3) must supply a platform for knowledge transfer. Finally, Bechky (2003), from her empirical research in a semiconductor equipment manufacturing company, found that BOs must invoke the necessary elements of work context and 
cannot be too abstract in order to facilitate a meaningful conversation between users working to resolve a problem.

\section{Map-to-I mprove (M2I)}

The M2I tool for process improvement was used in this research as a BO. Figures 1a to 1c present the M2I tool (with example) with the following 9-step analysis procedure: 1) identify problem area; 2) describe the problem; 3) draw diagram or flowchart of current state map where problem exists; 4) describe why the current system is wrong (not ideal) to cause the problem; 5) describe what needs to be done to fix the problem; 6) describe when it needs to be done; 7) describe who is responsible (key team players and/or key departments); 8) draw diagram or flowchart of future state map (targeted system) that will solve the problem; and 9) describe project success measurement plan. Steps 1 through 7 refer to "Plan", step 8 refers to "Do", and step 9 refers to "Study" of the PDSA cycle. The "Act" stage is the creation of new organizational work routines when they are proved worthy in step 9. In addition, M2I incorporates one more block to provide the date, addressing party, and the tool user. Researchers examining PDSA based-tools for process improvement in healthcare industry found that they are effective in improving work processes (Jimmerson et al., 2005; Spear, 2005; Ghosh and Sobek, 2006; Mazur and Chen, 2008). At the same time, experts highlight about potential pitfalls and traps of process improvement often leading to under-detection of true root-causes of errors (Repenning and Sterman, 2002). Specifically, PDSA based-tools should promote joined communication and behavioral change towards a common purpose in improving organizational work processes. In general, the literature suggests the following three rudiments for effective problem solving while using PDSA based-tools: 1) need for validation of current system knowledge against reality; 2) need for joint problem solving by affected parties; and 3) need for joint validation of new knowledge. Such rudiments were detected in hospitals that utilized "clinical microsystems" for organizational learning and delivery of care (Mohr et al., 2004). 


\begin{tabular}{|l|l|}
\hline Project Title (What are we trying to do?): & $\begin{array}{l}\text { Date: March 2007 } \\
\text { To: BDH Pharmacy Managers } \\
\text { By: BDH IE Group }\end{array}$ \\
\hline IV Delivery Process Improvement & Short Project Description (Concept/ Purpose/lmportance): \\
\hline $\begin{array}{l}\text { The IV Delivery Process takes place every day and is very important to the overall } \\
\text { performance of the hospital and the well-being of patients. There are numerous potentials } \\
\text { for errors and many inefficiencies in this process. The main goal of improvements is to } \\
\text { provide a safer process (with fewer medication errors) and to reduce waste (rework, } \\
\text { medications thrown away, etc.). It should be noted that waste usually results from caught } \\
\text { potential medication errors. Waste, therefore, will be reduced by decreasing the chance of } \\
\text { occurrence of these errors }\end{array}$
\end{tabular}

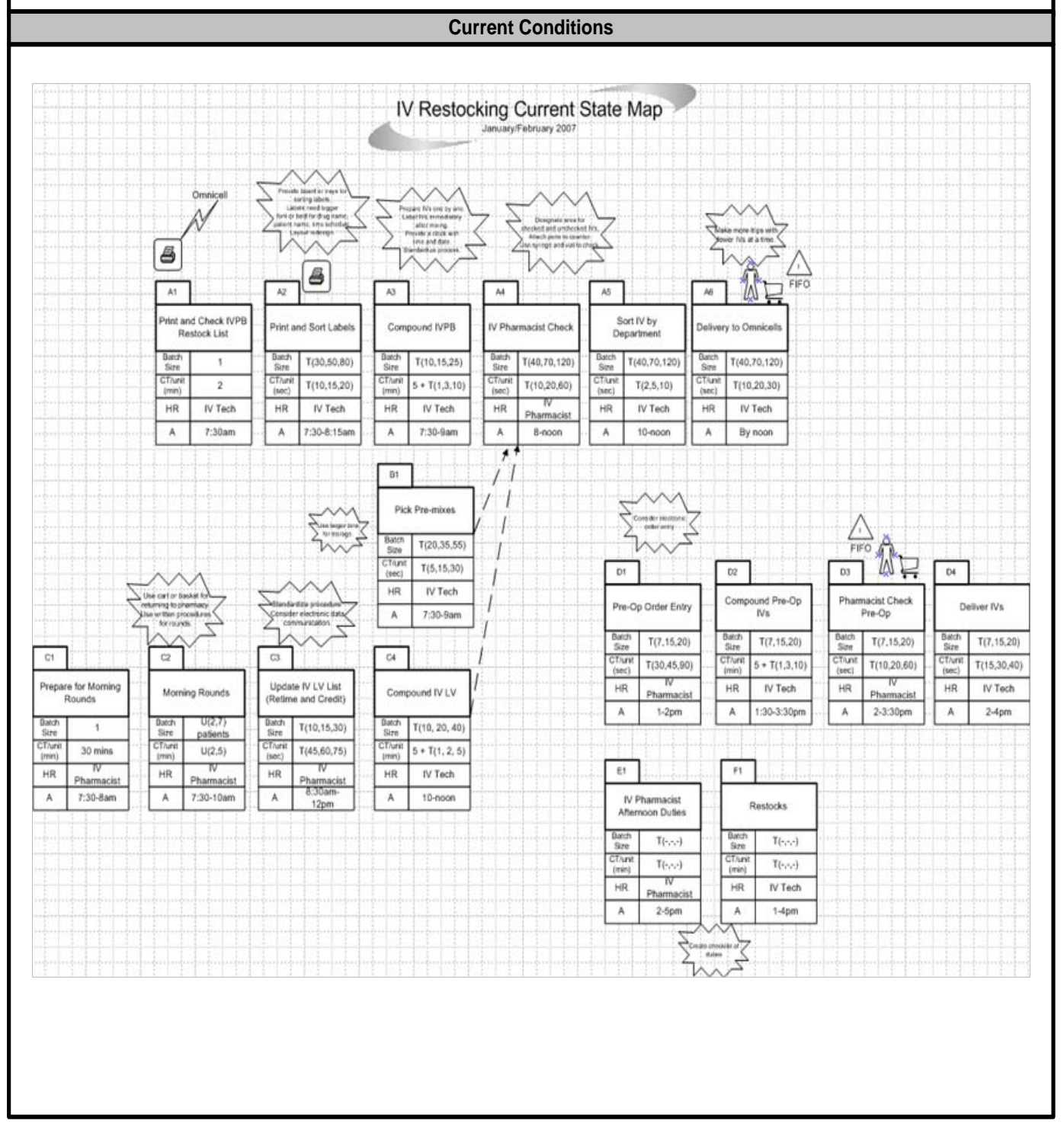

Figure 1a. "Map to Improve (M2I) Tool: Page 1". 


\begin{abstract}
What about the system is wrong (not IDEAL)?:
No standard procedures for many tasks.

Labels put on the wrong IVs (labels hard to read, technicians works on several IVs before

putting labels on them).

Picking wrong IVs from the shelves - problems with sound-alike/look-alike drugs.

Inefficient and low quality process of checking and sorting IVs due to space limitations - no

place to put prepared IVs so that they can be distinguished as checked/not checked.

Problems reading doctors handwriting.

Cart and bins used to deliver IVs are too small and result in dropping IVs and being forced to use floor as a work surface.
\end{abstract}

\title{
What needs to be done to fix problems (root causes)?:
}

Provide board/tray for label sorting.

Redesign labels to better communicate patient name, time schedule, drug name.

Look at layout redesign (of IV room).

Get bigger bins and cart for deliveries and provide more space for work surface.

Consider taking more than one trip with fewer IVs on the cart (alternative).

Designate areas for checked and unchecked IVs.

Standardize checking, sorting, and compounding processes.

Compound one IV at a time (keep one label under the hood) and put label on it immediately.

Provide a clock with time and calendar and hang it in a visible spot in IV room.

\section{When it is needed to be done?:}

There is no specific/required time to implement the improvements. However, the faster it will be done, the faster medication errors will decrease and process efficiency and quality will increase.

\section{Who is responsible (key team "players"; key departments involved)?}

Pharmacy managers should be responsible for leading and implementing improvement actions within the pharmacy

Pharmacists and technicians should be cooperative and active in implementation stage by providing feedback and communicating ideas

The hospital management should consider implementing physician computer order entry and improving the database updating process

Figure 1b. "Map to Improve (M2I) Tool: Page 2". 
Future Conditions

Diagram (flowchart) of Future (targeted) System:

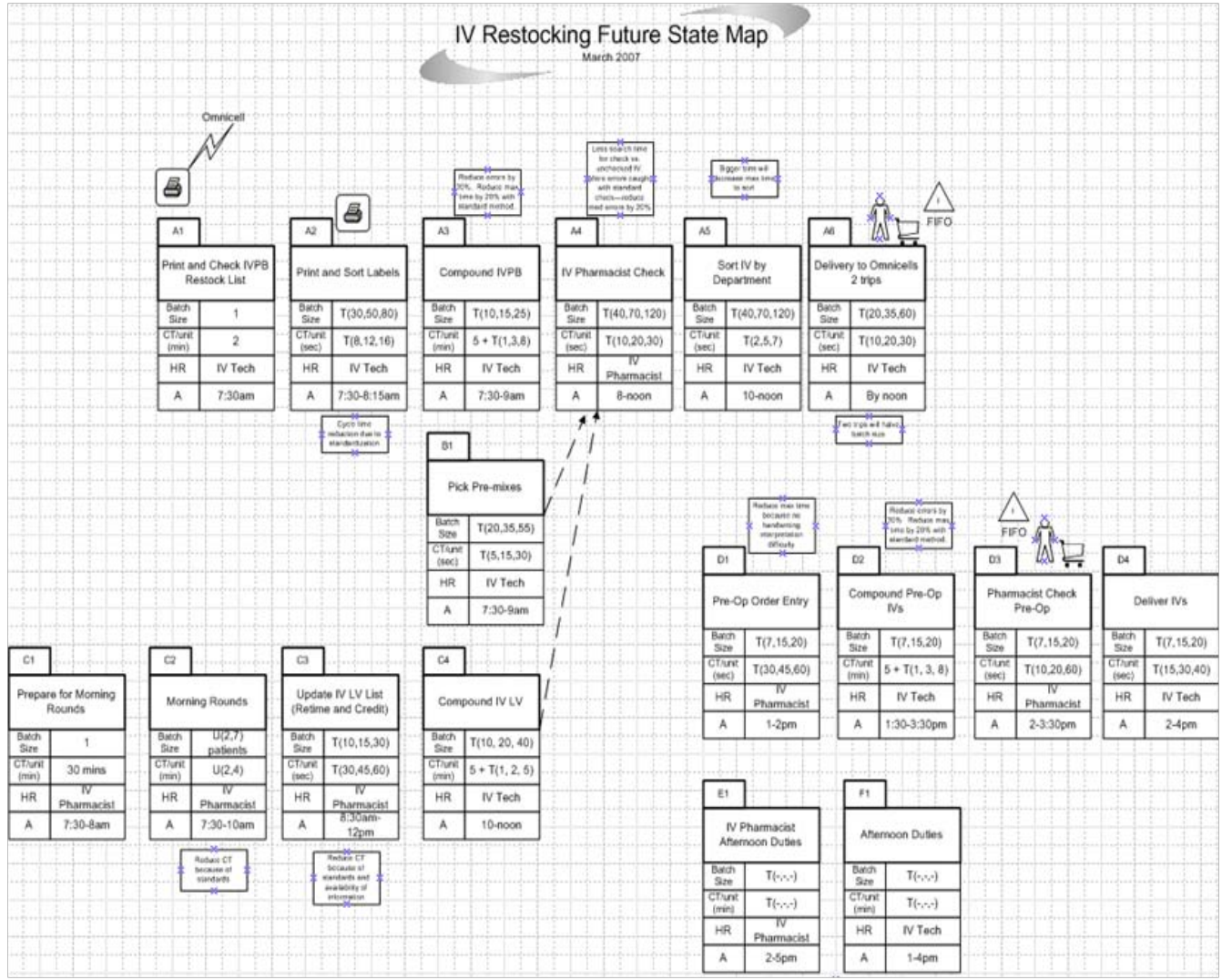

Project Success Measurement Plan:

Mostly qualitative.

The process should be more clear and better organized.

There should be less time when workers are idle.

Figure 1c. "Map to Improve (M2I) Tool: Page 3". 


\section{Research design and method}

The study was performed with fifteen senior-level IE students at two hospitals, namely Bozeman Deaconess Hospital in Bozeman, Montana and Rex Healthcare Hospital in Raleigh, North Carolina. The research team used the exploratory mixed method design approach to conduct this research (Gay et al., 2006; Driscoll et al., 2007). Quantitative data were collected using survey to identify characteristics that are perceived by IE students as instrumental while using PDSA analysis cycle embedded in the M2I tool. We also used unstructured conversation sessions with IE students and focus group meetings to collect data. We analyzed qualitative data using abductive inference in order to identify competencies needed by IEs for effective process improvement in hospital using PDSA based-tools (Pierce, 1934; Merton, 1957; Van de Ven, 2007). In general, we started with a set of facts derived from quantitative data analysis and then attempted to provide their most likely explanations using literature on BOs as a lens of an existing theory. We used abductive inference based on the insight that most developments in process improvement science and educational research cannot be explained by quantitative or qualitative data alone. Abductive inference was appropriate for our study setting because data from instructed conversations and focus group meetings created an opportunity to undertake in-depth study to "make sense" of quantitative data. Specifically, we used two primary considerations to arrive at final conclusions: 1 ) our explanations surpass any alternatives based on reliable data; and 2) our explanations, including the costs of being wrong and the benefits of being right, do not drive the need to come to a conclusion at all. Finally, in order to further elaborate on competences needed by IE students for effective process improvement using PDSA based-tools, we compared the findings from this study to the results obtained from an identical study with senior-level nursing students.

\subsection{Data collection}

First, all IE students were given two one-hour instructions to learn how to use the M2I tool to solve process improvement related problems. Because of students' IE background, we believe that two hours of training were sufficient before project initiation. Next, the students were assigned to multidisciplinary teams and were prompted to observe processes to better understand all potential factors influencing the studied problem. In addition to IE students, the multidisciplinary teams also 
involve hospital managers, nurses, and administrative employees. Once the participants gained an understanding of how the tasks are currently done within the process and developed a current state map, they were asked to consider how the system can be improved and draw a future state map of the system. The future sate map is a diagram of how the proposed system could work with the improvements in place. Throughout the study, we conducted weekly focus group meetings with the IE students. The conversation sessions allowed the researchers to collect more in-depth data to further understand "how" and "why" some of the analysis and improvement steps were accomplished. At any time during the study, all IE students were allowed to consult with the research team regarding any encountered problems with respect to the project. As such, throughout the project the students completed numerous cycles of PDSA on "mini-problems" allowing them to iterate through improvement cycles and improve their knowledge about problems. Upon completion of the project, we conducted a survey study using the instrument presented in Figures 1a-c. The survey instrument contained one positively and one reversed negatively worded close-ended questions for every predictor variable under study. In designing the instrument, the research team followed the guidelines provided by the literature (Aiman-Smith and Markham, 2004; Alreck and Settle, 2004). The survey instrument was kept short to maximize the rate of response without diluting the survey objectives. The survey instrument was administered to the IE students with a cover letter accepted by Internal Review Board (IRB). The cover letter explained to the IE students that this survey was voluntary, and they were free to stop at any time. Based on the literature review on process improvement tools and $\mathrm{BOs}$, the following predictor (we refer to predictor variables as characteristics of the tool), criterion, and control variables were used in this study.

I. Predictor Variables:

- Memorizing via organized documentation (Q1-Q2): the ability to remember information such as words, numbers, pictures, and procedures about the studied problem.

- Distilling and grouping information via drawing system map(s) (Q3-Q4): the ability to combine/arrange different pieces of information about the work processes.

- Brainstorming via visualization (Q5-Q6): the ability to understand about the root-cause(s) of the medication delivery problem. 
- Recognizing root-cause(s) of the problem via linking the process flow with task(s) characteristics (Q7-Q8): the ability to recognize the true rootcause(s) of the medication delivery problem.

- Generating creative improvement ideas via experimentation by drawing/redrawing system $\operatorname{map}(\mathrm{s})(\mathrm{Q} 9-\mathrm{Q} 10)$ : the ability to generate ideas to solve the root-cause(s) of the medication delivery problem.

- Communication via visual representation (Q11-Q12): the ability to facilitate communication with others via visual representation.

- Systems thinking via visualization (Q13-Q14): the ability to facilitate the improvement planning via visual representation.

- Selecting the improvement measures via linking the process flow with task(s) characteristics (Q15-Q16): the ability to select/develop the indicators to measure improvement with respect to the root-cause(s) of the medication delivery problem.

The IE students were asked to evaluate each survey question using a 5point Likert scale (from $1=$ strongly disagree to $5=$ strongly agree). For each predictor variable, the scores from negative questions were first reversed, then added to positive question, and averaged to arrive at a composite score for each prediction variable.

II. Criterion Variable (process improvement):

Process improvement (PI) is defined as the improvement in various process parameters (i.e., productivity, wasted time, number of errors, costs, and patient care) as a result of problem solving, as reported by the IE students. We reviewed all submitted M2I improvement reports from IE students after three months of data collection. Each M2I report was assessed using a 5-point Likert scale $(5 \mathrm{pt}=$ Very Good, 4 pts $=$ Good, 3pts Average, 2 pts Poor, 1pts Very Poor $)$ based on the binary decisions on the quality of their proposed solutions in terms of the following five evaluation questions (Yes $=1 \mathrm{pt}$, No $=0 \mathrm{pt}$ ):

1). Was the problem clearly defined?

2). Were the objectives met based on the identified major problems?

3). Were the proposed improvement actions feasible?

4). Were the implementation plans feasible? 
5). Were the improvement measurement plans feasible?

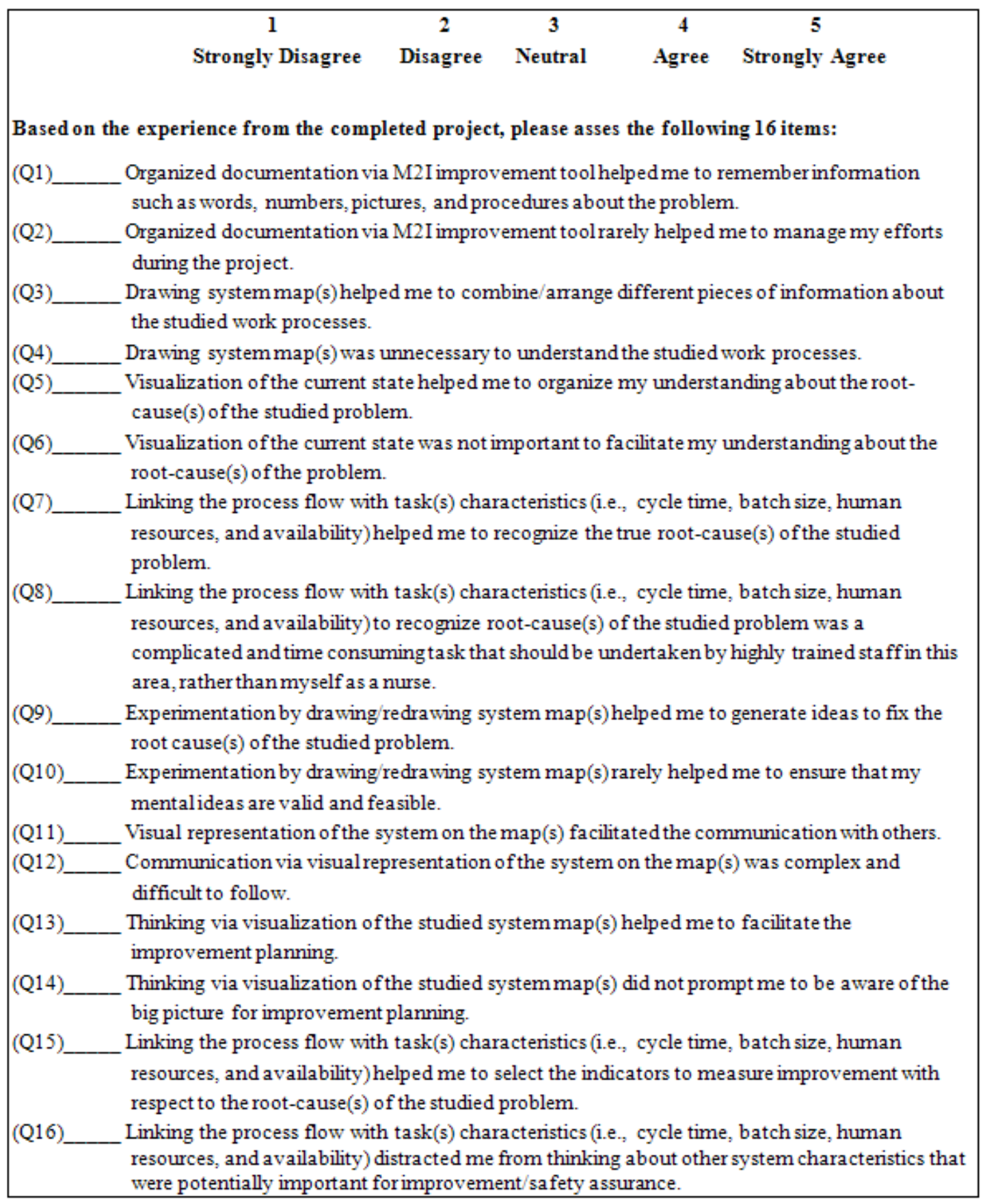

Figure 2. "Survey Instrument".

Evaluation points were assigned to each completed M2I report by student advisors on the project. Standardized evaluation helped us control assessment of the process improvement. The final analysis was done by adding up the scores from 
five evaluation questions to get a composite score for the criterion variable process improvement.

III. Control Variable (following the PDSA analysis procedure for problem solving): M2I requires executing certain key steps in the problem solving process. This control variable was used to investigate the potential effect it may have on the relationship between the predictor and criterion variables in process improvement. The research team assessed the control variable using a 5-point Likert scale (from $1=$ strongly disagree to $5=$ strongly agree) based on the binary decisions on whether IE students followed all 10 input boxes in the M2I tool shown in Figure 1 (was this M2I box filled? Yes $=0.25 \mathrm{pt}$, No $=0 \mathrm{pt}$ ) as well as filling the boxes correctly (was the content correct? Yes $=0.25 \mathrm{pt}$, No $=0 \mathrm{pt}$ ). The final score was derived by adding up the scores from the binary decisions to get a composite score for the control variable.

\subsection{Data analysis and results}

In this study, the M2I tool was used to identify characteristics that explain the efficacy of PDSA based-tools while used by IE students on multidisciplinary hospital teams. With the recommendations by Garsen (2002) for exploratory research with a relatively small sample size and subjectivity due to personal opinions/feelings, the significance level of 0.1 was set. Based on Anderson-Darling test for normality, the evidence suggested that all variables were normally distributed. The reliability measure of psychometric instrument was calculated using Cronbach's alpha for each set of questions under every testable predictor variable in the survey. All Cronbach's alpha results fell between 0.6 and 0.95 , an acceptable range to ensure reliability of the survey questions (Robinson et al., 1991). In general, literature recommends Cronbach's alpha values to be closer to 0.8 to ensure the internal consistency of survey questions. However, special cases are often made for accepting lower Cronbach's alpha values, particularly in research investigations exploring new "problems", especially during early stages of theory building. As such, having fairly small sample size of students conducting projects, while at the same time exploring challenging research subject, we did not drop variables with Cronbach's alpha less than 0.6 from our study and only one predictor variable (not significant in our study) scored below 0.7 . 
Table 1 represents bivariate correlations, means, and standard deviations for the predictor, control and criterion variables. All correlations between predictor variables were below 0.75 , the level commonly considered as problematic in qualitative research (Masson and Perreault, 1991). The evidence suggests that the criterion variable is positively correlated with all predictor variables. Table 2 represents the results of multiple regression analysis. The results indicate that Q5Q6 (brainstorming via visualization), Q7-Q8 (Recognizing root-cause(s) of the problem via linking the process flow with task(s) characteristics), and Q15-Q16 (selecting the improvement measures via linking the process flow with task(s) characteristics) are perceived by IE students as significant predictor variables of process improvement. The remaining predictor variables did not show a significant relationship with the criterion variable $(p>0.1)$.

\begin{tabular}{|l|c|c|c|c|c|c|c|c|c|c|}
\hline & Q1-Q2 & Q3-Q4 & Q5-Q6 & Q7-Q8 & Q9-Q10 & Q11-Q12 & Q13-Q14 & Q15-Q16 & Ct & Cr \\
\hline Q3-Q4 & 0.319 & & & & & & & & & \\
\hline Q5-Q6 & 0.071 & 0.17 & & & & & & & & \\
\hline Q7-Q8 & 0.292 & 0.334 & 0.25 & & & & & & & \\
\hline Q9-Q10 & 0.157 & 0.351 & 0.47 & 0.293 & & & & & & \\
\hline Q11-Q12 & 0.198 & 0.634 & 0.531 & 0.126 & 0.557 & & & & & \\
\hline Q13-Q14 & 0.185 & 0.679 & 0.448 & 0.467 & 0.578 & 0.518 & & & & \\
\hline Q15-Q16 & 0.245 & 0.6 & 0.192 & 0 & 0.541 & 0.708 & 0.508 & & & \\
\hline Control (Ct) & 0.354 & 0.48 & 0.409 & 0.018 & 0.116 & 0.627 & 0.449 & 0.674 & & \\
\hline Criterion Cr) & 0.322 & 0.732 & 0.581 & 0.415 & 0.668 & 0.859 & 0.778 & 0.809 & 0.708 & \\
\hline Mean & 4.733 & 4.533 & 4.233 & 4.2 & 3.8 & 4.4 & 4.133 & 4.300 & 4.233 & 4.40 \\
\hline s.d & 0.372 & 0.297 & 0.651 & 0.254 & 0.414 & 0.471 & 0.229 & 0.254 & 0.32 & 0.31 \\
\hline
\end{tabular}

Table 1. "Summary of Correlations, Means and Standard Deviations".

ANOVA calculations presented in Table 3 show that the differences in means of predictor variables are significant $(F-$ value $=42.65, \mathrm{p}<0.00)$. The normal probability plots, the fitted values plots, and the ordered plots of residuals indicated no concerns with respect to the adequacy of the regression model. 


\begin{tabular}{|l|c|c|c|c|}
\hline \multicolumn{5}{|c|}{ Regression Model } \\
\hline \multicolumn{1}{|c|}{ Predictor } & Coef & SE Coef & T & P \\
\hline Constant & -0.760 & 0.419 & -1.81 & 0.12 \\
\hline Q1 - Q2 & 0.099 & 0.070 & 1.41 & 0.207 \\
\hline Q3 - Q4 & 0.100 & 0.079 & 1.26 & 0.253 \\
\hline Q5 - Q6 & 0.239 & 0.075 & 3.15 & $* 0.02$ \\
\hline Q7 - Q8 & 0.129 & 0.052 & 2.46 & $* 0.049$ \\
\hline Q9 - Q10 & 0.070 & 0.102 & 0.69 & 0.517 \\
\hline Q11 - Q12 & 0.097 & 0.084 & 1.16 & 0.29 \\
\hline Q13 - Q14 & 0.155 & 0.111 & 1.39 & 0.213 \\
\hline Q15 - Q16 & 0.353 & 0.089 & 3.94 & $* 0.008$ \\
\hline
\end{tabular}

$S=0.105 R-S q=0.983 R-S q(\operatorname{Adj})=0.96$

Table 2. "Summary of Coefficient Analysis".

\begin{tabular}{|l|c|c|c|c|c|}
\hline \multicolumn{7}{|c|}{ ANOVA } \\
\hline \multicolumn{1}{|c|}{ Source } & DF & SS & MS & F & P \\
\hline Regression & 8 & 3.792 & 0.47396 & 42.65 & 0.00 \\
\hline Residual Error & 6 & 0.067 & 0.01111 & & \\
\hline Total & 14 & 3.858 & & & \\
\hline
\end{tabular}

Table 3. "Analysis of Variance for Regression Model".

\section{Discussion}

The results from correlation analysis suggested that the IE students perceived the M2I tool for process improvement as helpful in all studied predictor variables except remembering information such as words, numbers, pictures, and procedures about the studied problem (Q1-Q2). Using regression analysis, we found that the IE students perceive the M2I tool useful in brainstorming via visualization (Q5-Q6), recognizing root-cause(s) of the problem via linking the process flow with task(s) characteristics (Q7-Q8), and selecting the improvement measures via linking the process flow with task(s) characteristics (Q15-Q16). Also, the control variable (following the M2I analysis procedure for process improvement) was found to be correlated with process improvement $(r=0.708, p<0.00)$. 
From the unstructured conversations and weekly focus group sessions with IE students we learned that IE students tend to focus mostly on quantitative data alone (like cycle times, lead times, reliability indicators, and/or batch sizes) while performing analysis to identify root-causes. As such, they were able to efficiently and effectively utilize the M2I tool to graphically represent processes. IE students also strongly emphasized the "return on efforts/investment" devoted to creating M2I. The qualitative data analysis based on abductive inference allowed us to further investigate helpful competencies that IE students possess to effectively and efficiently use M2I on multidisciplinary teams for processes improvement and those that the IE students did not utilize well but would have improved their performance.

\subsection{Helpful competencies}

As IEs, students working with the M2I tool for process improvement effectively used two competencies: process visualization and synthesis of process characteristics for system improvement. First of all, IE students learn to brainstorm via visualization as they are taught to break processes into small pieces for problem-solving throughout their curriculum. The data students collected via observations and conversations at the frontline was used to map the entire process. IE students within the first two weeks of data collection broke the system into manageable pieces and then placed these manageable pieces into a high-level visual map. Mapping allowed IE students to visualize a system and its subcomponents. Visualization includes understanding the flow of a process from start to finish by means of diagrams, maps, and flowcharts. Therefore, process visualization was used by IE students to facilitate conversations and brainstorming with healthcare professionals participating in the project. As such, we discovered that the process representation embedded into M2I tool tended to lead the IE students and the team along certain steps of analysis which required reasoning at different levels of abstraction. Abstraction is the process of generalization by reducing the information content of a concept or an observable phenomenon, typically in order to retain only the relevant information for a particular purpose to make improvements in light of the big picture (Peschl and Stary, 1998; Lewis, 2006; Steif et al., 2010).

Graphical representations may be good or poor and many different forms of representation exist that each potentially contains only certain or limited 
information needed to fully understand the current system (Johnson, 1998). We found that representation that incorporates process characteristics (i.e., cycle time, batch size, and availability of human resources) critical to identify root-cause(s) of problems and selection of proper improvement measurement system required for the Study (S) phase of the PDSA cycle. This finding indicates that the use of basic flowcharts might be not sufficient for analysis of healthcare processes. Therefore, synthesis of process characteristics for system improvement emerged in our analysis as another competency that allowed IE students to make improvements in light of the big picture (i.e., the entire system). When decisions are made to improve specific tasks, a systems thinker must understand how the suggestion would affect other interrelated tasks. Decisions should be made that will improve the entire system. For example, IE students optimized the pharmacy schedule for medication delivery to nursing departments by taking into account process characteristics like batch size and/or cycle time of each process task. Such systemwide analysis supported by linking task characteristics with process flow turned out to be crucial for IE students in order to successfully develop, propose, and explain system-wide solution.

\subsection{Underdeveloped competencies}

While meeting with IE students, we discovered one category of competency to be potentially underdeveloped: documentation and understanding of data regarding hospital culture and change management process. There is little mentioned about obtaining and analyzing qualitative data in most undergraduate and even some graduate IE programs, as most IEs are mostly trained to analyze quantitative data. However, there is increasing evidence that success in achieving process improvement goals is at least partially attributable to implementation processes and change management contexts and not just to the nature of the technical solution. Documenting and understanding data about change management, personal beliefs and opinions, and/or how people learn in social environment proved to be very difficult for IEs. In our study, all IE students used different approaches to collecting and analyzing qualitative data which resulted in many discrepancies between the IE students and healthcare professionals leading to unnecessary misunderstandings and additional efforts to arrive at the agreeable solutions. What is more, much of the analysis was done on the quantitative data, while the qualitative data was only discussed, but not formally analyzed, thus 
making conclusions on the qualitative part weaker. The important competency to notice is that documenting and understanding "qualitative" data might be as critical as quantitative analysis with survey data. Without this knowledge, it might be difficult for IE students to be successful in hospital environments.

\subsection{Comparison to nursing students}

Mazur and Chen (2008a) performed an identical study with fifteen senior-level nursing students. The results from correlation analysis suggested that nursing students perceived the M2I tool to be helpful in remembering information such as words, numbers, pictures, and procedures about the studied problem (Q1-Q2 with $r=0.78, p<0.00)$, and in facilitating the improvement planning process via visual representation (Q13-Q14 with $r=0.46, p=0.09$ ). The control variable was also found to be correlated with process improvement $(r=0.92, p<0.00)$. Surprisingly, the nursing students indicated that the brainstorming via visualization of current state $\operatorname{map}(\mathrm{s})$ does not facilitate the understanding about the rootcause(s) of the problem (Q5-Q6 with $r=-0.45, p=0.09$ ). From regression analysis, the nursing students found the M2I tool useful only in remembering information (Q1-Q2 with $r=0.78, \mathrm{p}<0.00)$.

From qualitative analysis, Mazur and Chen (2008a) found that most root-causes of problems under investigation by the entry-level nurses were grounded in qualitative phenomena like vigilance/compliance, psychological safety, productivity pressures, and/or cultural barriers. As such root-causes were very hard to be represented and analyzed graphically via mapping, the nursing students indicated that the "return on efforts/investment" devoted to creating, communicating, and analyzing processes via M2I as neutral. Therefore, combining the two studies together, we believe that process improvement using PDSA based-tools can be difficult and dramatic, as students with varied educational backgrounds perceived and analyzed problems embedded in hospital processes differently. As such, forcing nurses and IEs, or perhaps any combination of medical and process improvement professionals, into multidisciplinary teams is not trivial, as speed and information processing of analysis differ. We believe that education on healthcare process improvement in engineering and nursing/medical academic settings should be placed under critical review and improvement cycle. Further research on training methods about multidisciplinary process improvement is needed as it enables fixing 
healthcare from the 'inside-out', and has opportunity to save thousands of lives by creating stable and reliable processes. Without educational training, hospitals will continue to hire professionals that solve problems in isolation, a way that negatively affects other areas, and eventually harms patient care.

\section{Limitations}

The following obstacles were identified. First, this study was conducted only in two organizational settings. Second, data collection by researchers presented several difficulties: 1) unstructured conversations and focus group meetings can alter responses and behavior (also known as Hawthorne effect), particularly motivating students to respond more positively about their experiences in hospital settings (Burke et al., 2000); 2) the fact that all IE students had limited experience in hospital settings possibly hindered their abilities to understand some of the events witnessed; and 3) the unknown bias of the researchers, which could influence what was recorded, coded and analyzed, could be present in this research (Miles and Huberman, 1994). Third, the effects of problem format, number of independent variables, and their interactions on student reasoning and problem-solving ability could not be fully controlled, potentially affecting students' performance (Staver, 1986; Goldstein and Levin, 1987). Fourth, the study did not have a control group. Comparing the results between the intervention groups and the control groups (i.e., IE students performing improvement projects without using the M2I method) would have given more credibility to the research outcomes. Fifth, only one particular instrument, M2I, was used. However, different instruments could influence the cognitive information processing of individuals, changing the analysis outcomes to some degree. Sixth, this study used a specific set of performance measures focusing on the project outcomes. Future work should focus on using multiple instruments and multiple measures (i.e., increased satisfaction, increased knowledge, etc.) for determining the effects of an intervention on students. Using such multiple instruments and measures will provide more robust results and protect against potential interpretive errors. Seventh, another shortcoming of this research was the small sample size of students. A larger sample size, perhaps representing different populations (i.e., different genders, ethnic groups, etc.), would have given more statistical power to the survey data and results. It is important to mention that mixed method designs for exploring complex research objectives, like the one in this paper, can still provide a deep understanding of 
survey responses via qualitative analysis of data, and provide detailed assessment of patterns of responses via statistical analysis. Due to the limitations including sample size, this research provides a set of recommendations that are grounded in statistical analysis which do not represent cause-and-effect relationships. Furthermore, because the mixed method research is time consuming it often leads researchers working under tight budget and time constraints to reduce sample size or limit the time spent in the field. Eighth, the survey study was administered at one point in time, meaning that the survey study was cross-sectional. Therefore, establishing definitive causal relationships among the study variables was not possible. The results would have had more validity if a longitudinal survey design was used with the survey data collection replicated at multiple points in time. Finally, this study was conducted in the inpatient hospital areas. Future research should also investigate the possibility of applying PDSA based-tools in the areas of outpatient. Therefore, based on the limitations of this study, generalization of the findings to the entire population of IE students cannot be ascertained.

\section{Conclusions}

The challenge is to manage the growing knowledge of process improvement and ensure that future IEs will have the competencies needed to utilize PDSA basedtools to analyze and improve healthcare delivery. The ability to analyze processes is absolutely critical to the healthcare industry. However, process analysis and the resulting improvements performed by IEs in hospitals are not well understood. This research identifies characteristics that explain the efficacy of PDSA based-tools while used by IE students working on multidisciplinary hospital teams. These characteristics are: 1) brainstorming via visualization; 2) recognizing root-cause(s) of the problem via linking the process flow with task(s) characteristics; and 3 ) selecting the improvement measures via linking the process flow with task(s) characteristics. By performing qualitative analysis on data collected using unstructured interviews and focus group meetings, and by comparing the findings to the results obtained from an identical study with senior-level nursing students, we discussed about helpful and underdeveloped competencies needed for multidisciplinary process improvement in hospitals. In general, the helpful competencies focus on visualizing and linking process characteristics (i.e., cycle time, batch size, and availability of human resources) with process flow to identify root-cause(s) of problems, which in turn allows IE students to select proper 
improvement measurement system required for the Study (S) phase of the PDSA cycle. Such competencies were lacking in nursing students. The underdeveloped competencies included documentation and understanding of data regarding hospital culture and change management process. Oppositely, nursing students presented strong competencies in documenting, analyzing, and interpreting such qualitative data.

We hope that the proposed insights into these areas will result in improved strategies for educational training and professional development of future IEs and healthcare providers. If IE tools and practices are independently transformed to healthcare industry without the in-depth understanding about how to use them in such new environments, they will likely impose an unnatural collaboration and result in unsatisfactory solutions. Therefore, with the emerging knowledge, we encourage IE programs to consider incorporating qualitative data and context analysis into statistically-driven problems that are introduced to students throughout the IE curriculum. We also recommend close collaboration with nursing and medical schools to properly incorporate systems engineering methods/tools into educational curriculum. The practical implication of this research extends to the development of better methods/tools for process improvement. It is essential that improvement strategies should be developed to enhance a natural collaboration of multidisciplinary teams. In summary, we believe that once students are provided with the proper educational training, the performance of process improvement in all hospital settings will be greatly increased.

\section{Acknowledgments}

We would like to thank all participating students for their diligent work in collecting and analyzing data. Without their professionalism and expertise, this research could not be accomplished. We also would like to express our gratitude to Bozeman Deaconess Hospital and Rex Healthcare Hospital for hosting and providing environment throughout project execution.

\section{References}

Alreck, P. L., \& Settle, R. B. (2004). The survey research handbook. New York: McGraw-Hill/Irwin. 
Aiman-Smith, L., \& Markham, S. K. (2004). What you should know about using surveys. Research Technology Management, 47(3), 12-15.

Anderson, J. G., Ramanujam, R., Hensel, D., Anderson, M. M, \& Sirio, C. A. (2006). The need for organizational change in patient safety. International Journal of Medical Informatics, 75, 809-817.

doi:10.1016/j.ijmedinf.2006.05.043

Bechky, B. (2003). Sharing meaning across occupational communities: The transformation of understanding on a production floor. Organization Science, 14(3), 312-330.

doi: $10.1287 /$ orsc. 14.3 .312 .15162

Berg, M., \& Bowker, G. (1997). The multiple bodies of the medical record: Toward a sociology of an artifact. The Sociological Quarterly, 38(3), 513-537.

doi:10.1111/j.1533-8525.1997.tb00490.x

Brown, J. S., \& P. Duguid. (1998). Organizing knowledge. California Management Review, 40(3), 90-110.

Burke, T. A., McKee, J. R., Wilson, H. C., Donahue, R. M. J., \& Batenhorst, A. S., et al. (2000). A comparison of time-and-motion and self-reporting methods of work measurement. J ournal of Nursing Administration, 30(3), 118-125. doi:10.1097/00005110-200003000-00003

Carlile, P. (2002). A pragmatic view of knowledge and boundaries: Boundary objects in new product development. Organization Science, 13(4), 442-455. doi: $10.1287 /$ orsc. 13.4 .442 .2953

Carlile, P. (2004). Transferring, translating, and transforming: An integrative framework for managing knowledge across boundaries. Organization Science, 15(5), 555-568.

doi: $10.1287 /$ orsc. 1040.0094

Deming, W. (1986). Out of the crisis. Cambridge, Mass: Massachusetts Institute of Technology, Center for Advanced Engineering Study. 
Driscoll, D. L., Appiah-Yeboah, A., Salib, P. \& Rupert, D. J. (2007). Merging qualitative and quantitative data in mixed methods research: How to and why not. Ecological and Environmental Anthropology, 3(1), 19-28.

Dutton, J. (1993). The making of organizational opportunities: An interpretive pathway to organizational change, In L. L. Cummings, and B. M. Staw (Eds.), Research in organizational behavior (pp. 195-226). Greenwich, CT: JAI Press.

Garsen, D. (2002). Guide to writing empirical papers, thesis and dissertation, New York: Marcel Dekker, Inc.

Gay, L. R., Geoffrey, E. M. \& Airasian, P. (2006). Educational research: Competencies for analysis and application. New Jersey: Pearson Education.

Ghosh, M. \& Sobek, D. K. (2006). A test of the design rules in health care. In Proceedings, industrial engineering research conference.

Goldstein F. C., \& Levin H. S. (1987). Disorders of reasoning and problem-solving ability. In M. Meier, A. Benton, and L. Diller (Eds.), Neuropsychological rehabilitation. London: Taylor and Francis Group.

Hackman, J. R., \& Wageman, R. (1995). Total quality management: Empirical, conceptual, and practical issues. Administrative Science Quarterly, 40(2), 309342.

\section{doi: $10.1287 /$ orsc. 1040.0094}

Henderson, K. (1991). Flexible sketches and inflexible databases: Visual communication, conscription devices, and boundary object in design engineering. Science, Technology, and Human Values, 16(4), 448-473.

doi: $10.1177 / 016224399101600402$

Henderson, K. (1995). The political career of a prototype: Visual representation in design engineering. Social Problems, 42(2), 274-299.

doi: $10.1525 /$ sp. $1995.42 .2 .03 \times 0114 j$

Henderson, K. (1998). The role of material objects in the design process: A comparison of two design cultures and how they contend with automation. 
Science, Technology, and Human Values, 23(2), 139-174.

doi: $10.1177 / 016224399802300201$

Huq, Z., \& Martin, T. N. (2000). Workforce cultural factors in TQM/CQI implementation in hospitals. Health Care Management Review, 25(3), 80-93.

Institute of Medicine. (2005). Building a better delivery system: a new engineering/heath care partnership. A report of the Institute of Medicine, Washington, DC.

Jimmerson, C., Weber, D., \& Sobek, D. K. (2005). Reducing waste and errors: Piloting lean principles at IHC. Joint Commission Journal on Quality and Safety, 31(5), 249-257.

Johnson, S. (1998). What's in a representation, why do we care, and what does it mean? Examining evidence from psychology. Automation in Construction, 8, 1524.

doi: $10.1016 / 50926-5805(98) 00062-4$

Lei, D., Hitt, M. A., \& Bettis, R. (1996). Dynamic core competencies through metalearning and strategic context. Journal of Management, 22(4), 549-569.

doi:10.1177/014920639602200402

Lewis, J. (2006). Cortical networks related to human use of tools. The Neuroscientist, 12(3), 211-231.

doi: $10.1177 / 1073858406288327$

MacDuffie, J. (1997). The road to "root cause": Shop-floor problem-solving at three auto plants. Management Science, 43(4), 479-502.

doi: $10.1287 / \mathrm{mnsc} .43 .4 .479$

Mason, C. H., \& Perreault, W. D. (1991). Collinearity, power, and interpretation of multiple regression analysis. J ournal of Marketing Research, 23, 268-280.

doi: $10.2307 / 3172863$

Mazur, L.M., Chen, S-J., \& Prescott, B. (2008). Pragmatic evaluating of Toyota Production System (TPS) analysis procedure for problem solving with entry-level 
nurses. J ournal of Industrial Engineering and Management, 1(2), 240-268. doi:10.3926/jiem.2008.v1n2.p240-268

Mazur, L. M., \& Chen, S. J. (2008b). Understanding and reducing waste due to medication errors via systems mapping and analysis. Health Care Management Science, 11(1), 55-65.

doi: $10.1007 /$ s10729-007-9024-9

Merton, R. (1957). Social theory and social structure (rev. ed.). Glencoe, IL: Free Press.

Miles, M. B., \& Huberman, A. M. (1994). Qualitative data analysis: an expanded sourcebook. Sage, Thousand Oaks, CA.

Mohr, J. J., Batalden, P \& Barach, P. (2004). Integrating patient safety into the clinical microsystem. Quality and Safety in Health Care, 13(6), 34-38.

Pierce, C. (1934). In C. Hartshorne and P. Weiss (Eds.), Collected papers of Charles Sanders Pierce, Volume V: Pragmatism and pragmatistic logic. Cambridge, MA: Harvard University Press.

Pelled, L. H., Eisenhardt, K. M., \& Xin, K. R. (1999). Exploring the black box: An analysis of work group diversity, conflict, and performance. Administrative Science Quarterly, 44(1), 1-28.

doi: $10.2307 / 2667029$

Peschl, M. \& Stary, C. (1998). The role of cognitive modeling for user interface design representations. Minds and Machines, 8, 203-236.

doi: $10.1023 / \mathrm{A}: 1008223113903$

Repenning, N. P., \& Sterman, J. D. (2002). Capability traps and self-confirming attribution errors in the dynamics of process improvement. Administrative Science Quarterly, 47(2), 265-295.

doi: $10.2307 / 3094806$

Robinson, J. P., Shaver, P. R., \& Wrightsman, L. S. (1991). Criteria for scale selection and evaluation: Measures of personality and social psychological attitudes. San Diego: Academic Press. 
Soo, C., Vevinney, T., Midgley, D., \& Deering, A. 2002. Knowledge management: Philosophy, processes, and pitfalls. California Management Review, 44(4), 129150.

Spear, S.J. (2005). Fixing healthcare from the inside, today. Harvard Business Review, 83(9), 78-91.

Star, S. L., \& Griesemer, J. R. (1989). Institutional ecology, 'Translations' and boundary objects: Amateurs and professionals in Berkeley's museum of vertebrate zoology. Social Studies of Science, 19(3), 387-420.

doi:10.1177/030631289019003001

Staver, J.R. (1986). The effects of problem format, number of independent variables, and their interaction on student performance on a control of variable reasoning problem. J ournal of Research in Science Teaching, 23(6), 533-542.

doi: $10.1002 /$ tea. 3660230606

Steif, P. S., Lobue, J. M., Kara, L. B., \& Fay, A. L. (2010). Improving problem solving performance by inducing talk about salient problem features. Journal of Engineering Education, 99(2), 135-142.

Van de Ven, A. H., (2007). Engaged scholarship: A guide for organizational and social research. New York: Oxford University Press.

Yakura, E. K. (2002). Charting time: Timeliness as temporal boundary objects. Academy of Management J ournal, 45(5), 956-970.

doi: $10.2307 / 3069324$

Journal of Industrial Engineering and Management, 2010 (www.jiem.org)

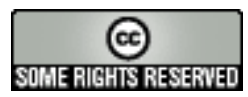

Article's contents are provided on a Attribution-Non Commercial 3.0 Creative commons license. Readers are allowed to copy, distribute and communicate article's contents, provided the author's and Journal of Industrial Engineering and Management's names are included. It must not be used for commercial purposes. To see the complete license contents, please visit http://creativecommons.org/licenses/by-nc/3.0/. 